\title{
Persistent clinical efficacy and safety of anti-tumour necrosis factor $\alpha$ therapy with infliximab in patients with ankylosing spondylitis over 5 years: evidence for different types of response
}

\author{
J Braun, ${ }^{1}$ X Baraliakos, ${ }^{1} \mathrm{~J}$ Listing, ${ }^{2}$ C Fritz, ${ }^{2}$ R Alten, ${ }^{3}$ G Burmester, ${ }^{4}$ A Krause, ${ }^{5}$ \\ S Schewe, ${ }^{6}$ M Schneider, ${ }^{7}$ H Sörensen, ${ }^{8}$ H Zeidler, ${ }^{9}$ J Sieper ${ }^{10}$
}

${ }^{1}$ Rheumatology Medical Center Ruhrgebiet, Herne; ${ }^{2}$ German Rheumatism Research Center, Berlin; ${ }^{3}$ Schlosspark Clinic, Berlin; ${ }^{4}$ Charité Hospital, Humboldt University, Berlin; ${ }^{5}$ Berlin-Buch Hospital, Berlin:

${ }^{6}$ Ludwig-Maximilians-University, Munich; ${ }^{7}$ Heinrich-Heine-

University, Düsseldorf;

${ }^{8}$ Immanuel Hospital, Berlin;

${ }^{9}$ Medical University, Hannover,

${ }^{10}$ University Medicine Berlin,

Campus Benjamin Franklin, all Germany

Correspondence to: Prof. Dr. J Braun,

Rheumazentrum Ruhrgebiet, Landgrafenstr. 15, 44652 Herne, Germany; j.braun@

rheumazentrum-ruhrgebiet.de

Accepted 2 October 2007 Published Online First 29 October 2007

\section{ABSTRACT}

Background: There is insufficient evidence for the longterm efficacy and safety of anti-tumour necrosis factor therapy in patients with ankylosing spondylitis (AS). This is the first report on the treatment with infliximab over 5 years.

Methods: As part of a multicentre randomised trial, 69 patients with active AS at baseline (BL) have been continuously treated with infliximab $(5 \mathrm{mg} / \mathrm{kg}$ i.v. every 6 weeks) - except for a short discontinuation after 3 years (FU1). The primary outcome of this extension was remission according to the ASsessment in Ankylosing Spondylitis (ASAS) criteria at the end of year 5 of the study (FU2).

Results: Of the 43 patients who completed year 3, 42 agreed to continue, 38 of which (90.5\%) finished year 5 (55\% of 69 initially). Partial clinical remission was achieved in 13 of 38 patients (34.2\%) at FU1 and FU2. At FU2, the mean Bath Ankylosing Spondylitis Disease Activity Index (BASDAl) was 2.5 \pm 1.9 (BL:6.4, FU1:2.5). BASDAl values $<4$ were seen in $79 \%$ of patients at both, FU1 and FU2. ASAS 20\% and 40\% responses were seen in $32(84 \%)$ and $24(63 \%)$ patients at FU2, respectively. Most patients classified as non-responders at FU2 were part-time responders, as all but one patient achieved an ASAS 20\% response at least once within the last 2 years. Three types of responders were identified. No major side effects occurred during years 4 and 5 of infliximab therapy.

Conclusions: Infliximab is safe and efficacious in AS patients over 5 years. The majority of the patients remained on treatment and had rather persistent levels of low disease activity. Different response types could be identified.

Ankylosing spondylitis (AS), the prototype of the spondyloarthritides, is a frequent chronic inflammatory disease with a prevalence of about $0.5 \% .{ }^{1-4}$ AS affects mostly young patients in the second and third decade of life. ${ }^{1}$ Owing to the substantial burden of disease, ${ }^{5}$ definite direct and indirect costs are substantial ${ }^{6-8}$ and absence from work and work disability are reportedly threefold increased in AS patients. $^{8-10}$

The short-term efficacy of the monoclonal antitumour necrosis factor $\alpha$ (TNF- $\alpha$ ) infliximab has been demonstrated in several studies on patients with active AS. Recently, we reported on the impressive clinical efficacy seen in patients treated with infliximab in a 12 -week, double-blind, placebo-controlled study. ${ }^{11}$ The clinical efficacy was maintained in several open-label extension phases of this study in which patients were treated continuously with infliximab infusions of $5 \mathrm{mg} / \mathrm{kg}$ every 6 weeks for up to 3 years. ${ }^{12-14}$ After a short phase of discontinuation and restart of infliximab therapy because of clinical relapse patients received continuous treatment with the TNF blocker. Magnetic resonance imaging (MRI) examinations of the same patients showed a significant decrease of inflammatory spinal lesions in the infliximab but not in the placebo group..$^{15}$

Here we report the clinical results of the 5-year extension of this study.

\section{METHODS}

\section{Patients and study protocol}

The results of the 12 -week, randomised, placebo controlled phase of the study, ${ }^{11}$ also of the 1-, 2and 3-year extensions have been previously reported. ${ }^{12} 1416$ Briefly, 69 patients with severe and active AS randomly selected at baseline (BL) of the initially placebo controlled phase of the study were assigned to receive infliximab $5 \mathrm{mg} / \mathrm{kg}$ or placebo for 12 weeks. At week 12, patients initially assigned to placebo switched to infliximab $(5 \mathrm{mg} / \mathrm{kg} / 6$ weeks). All patients continued infliximab treatment for 3 years. Disease activity at BL was assessed by the Bath Ankylosing Spondylitis Disease Activity Index $\left(\mathrm{BASDAI}^{17}\right)$. A score of at least 4 and a spinal pain score of at least 4 (on a numerical rating scale ranging from 0 to 10 ) was required for inclusion. Concomitant disease-modifying antirheumatic drugs (DMARDs) and oral corticosteroids were not allowed during the study. Use of non-steroidal anti-inflammatory drugs (NSAIDs) was permitted, and dosages of NSAIDs were allowed to be reduced but not increased during the study.

After having completed the third year, ${ }^{14}$ patients were asked to discontinue infliximab. Thereafter they were visited regularly to determine the time to flare. ${ }^{18}$ A relapse was defined as a BASDAI ${ }^{17}$ value $\geqslant 4$ and physician's global assessment (PhysGA) $\geqslant 4$ according to the ASsessment in Ankylosing Spondylitis (ASAS) recommendations. ${ }^{19}$ In the case of relapse, the patients were reinfused with infliximab at the same dosage with the same intervals until the end of year 5 of the study. Most patients relapsed within 18-24 weeks. ${ }^{18}$ 
The study medication was manufactured by Centocor, Inc. (Malvern, PA, USA), and was packaged and labelled by Essex Pharma (Munich, Germany). The local independent ethics committees approved the original study protocol and all extension including the one for year 5. All patients who participated in this extension gave written informed consent.

\section{Assessments}

The disease status was assessed by using validated parameters for disease activity (BASDAI), metrology (Bath AS Metrology Index $(\mathrm{BASMI})^{20}$ ), function (Bath AS Functional Index $(\text { BASFI })^{21}$ ), patient's (PatGA) and physician's (PhysGA) global assessments, and spinal pain (P). All parameters were measured using a numeric rating scale ranging from 0 to 10 .

Peripheral arthritis was assessed by counting the number of swollen joints out of a total of 64 joints. ${ }^{11}$ Other reasons for joint pain, tenderness or swelling had to be excluded clinically and/or by imaging if necessary. Health-related quality of life was assessed using the Short Form (SF)-36 questionnaire..$^{22}$ The scoring algorithm of the Medical Outcome Trust ${ }^{23}$ was used to calculate the SF-36 physical and mental component summary scores.

The laboratory parameters for inflammation C-reactive protein (CRP) and erythrocyte sedimentation rate were measured in all patients. The normal value for CRP is $<6 \mathrm{mg} /$ $\mathrm{dl}$ and for erythrocyte sedimentation rate $<20 \mathrm{~mm} / 1$ hour.

The primary outcome parameter was the proportion of patients with partial clinical remission at the end of the fifth study year (FU2) in comparison with $\mathrm{BL}$, and to the end of the third (FU1) study year (the time point before infliximab discontinuation and readministration). Partial remission was defined as a score $\leqslant 2$ (on a scale of $0-10$ ) in each of the four ASAS Working Group domains: ${ }^{24}$ PatGA, NRS-P, function (represented by the BASFI score), and morning stiffness (represented by the mean of the two morning stiffness scales of the BASDAI). At the end of year 5 , treatment response was also assessed by calculating a 50\% improvement of the BASDAI, by a $40 \%$ improvement in the ASAS improvement criteria and by the "ASAS 5 out of 6 " criteria. ${ }^{25}$ To meet the "ASAS 5 out of 6 " criteria, a $20 \%$ improvement in any five of the following six domains is required: the four domains used for partial remission, and in addition spinal mobility (as assessed by the BASMI) and CRP as acute phase reactant.

Finally, the cut-off for the definition of a low disease activity state was set at a BASDAI value $<3$ units, as previously proposed $^{26}$ and definition of high disease activity was set as a $\mathrm{BASDAI} \geqslant 4$ units, which was also the inclusion criterion for the study at $\mathrm{BL}$ and at infliximab readministration. ${ }^{1126}$

\section{Statistical analysis}

For the analysis of the primary outcome parameter, data of the 38 patients who had completed the fifth study year were used. To compare the mean differences between time points (BL versus FU1 and FU2), a paired t-test was applied. In the case of skewed distributions (CRP and erythrocyte sedimentation rate) the non-parametric Wilcoxon test was used. McNemar test was applied in the case of proportions. Groups of patients were compared using the Mann-Whitney test.

\section{RESULTS}

The results of the 3 -month placebo controlled phase, ${ }^{11}$ and the first 3 years of the study have been previously reported. ${ }^{12} 1416$ Forty-three of the original 69 patients (62\%) completed year 3 and 42 patients agreed to continue with the next phase for another 2 years. At the end of year 5, four of 42 patients $(9.5 \%)$ had withdrawn from the study for various reasons: One patient withdrew because of planned pregnancy, two other patients preferred to receive reimbursed medication by her rheumatologist (fig 3). The remaining patient had experienced a serious adverse event (see below). Thus, at the end of the fifth year, 38 patients were still in the study $(55.1 \%$ of 69 patients at BL and $90.5 \%$ of 42 patients who entered this extension phase). The mean age at $\mathrm{BL}$ of these 38 completers was 38.7 (8.1) years, $71.1 \%$ were male and $94.6 \%$ HLA-B27 positive.

\section{Efficacy}

\section{Remission}

When analysing the proportion of responders, the efficacy of infliximab at years 4 and 5 of the study appeared to be similar to the status at the end of year 3 (before infliximab discontinuation). The primary outcome parameter, partial clinical remission, was achieved by 13 of 38 patients at FU 2 (34.2\%), as compared with 14 of $38(36.8 \%)$ at FU1 ( $p=N S$ ) (fig 1). Of interest, seven of 38 patients (18.4\%) were in clinical remission at both time points, 12 weeks after the first infusion of infliximab and at FU2. This means that, of the 13 patients who were in clinical remission after 5 years, seven (53.8\%) had already been in clinical remission at 12 weeks (after three infusions). Similarly, 10 of 38 patients (23.7\%) patients were in clinical remission 24 weeks after the start of infliximab therapy and also at FU. This implies that the 10 of 13 completers $(76.9 \%)$ who had been in remission already after five infliximab infusions were also in clinical remission after 5 years of therapy. This was not different for other time points during the first 3 years of the study until the discontinuation of infiximab.

\section{Patient states}

When analysing patient states, the efficacy of infliximab also appeared to persist over 5 years, with similar values for the clinical assessments at follow-up. After 5 years the mean BASDAI was 2.5 (1.9) (BL: 6.4, FU1: 2.5) and the mean CRP was 3.4 (3.9) (BL: 27.7, FU1: 3.2) mg/dl, the mean BASFI was 3.0 (2.4) (BL: 5.4, FU1: 2.9), the mean PatGA 2.7 (2.2) (BL: 7.0, FU1: 2.6) and the mean BASMI was 2.8 (2.1) (BL: 3.6, FU1: 2.6) (all $p<0.05$ compared with BL and $p=N S$ between FU1 and FU2). As shown in fig $2 \mathrm{a}$, the individual parameters of all assessments

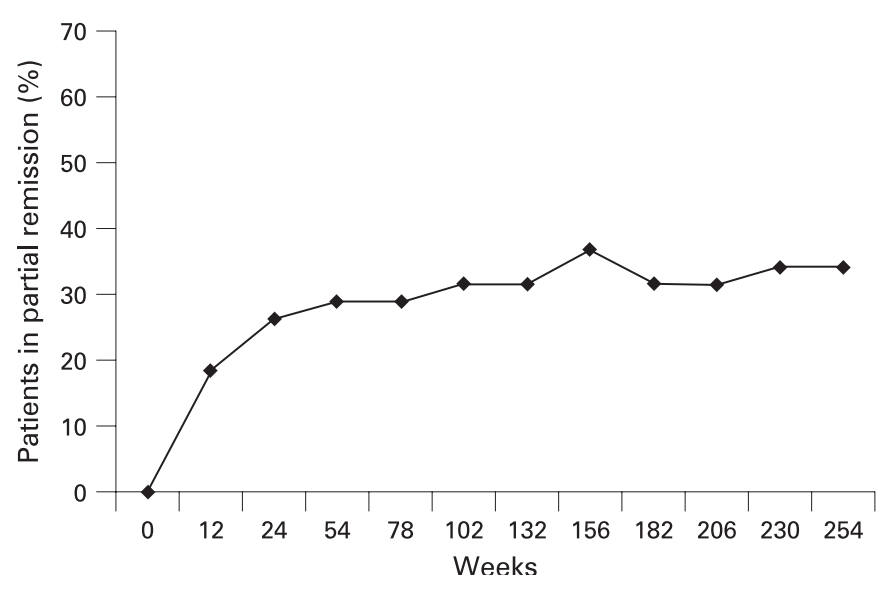

Figure 1 Completer analysis of patients in partial remission after 5 years of treatment with infliximab. 
remained at a low level similar to the first and second year of the study.

After 5 years, a low disease activity state (BASDAI value $<3$ units) was reached by 22 of 38 patients $(57.9 \%)$ and a $\mathrm{BASDAI}<4$ units was reached by 30 of 38 patients $(78.9 \%)$. In comparison, before infliximab discontinuation BASDAI values $<3$ units were reached by 20 of 38 patients $(52.6 \%)$ and BASDAI valued $<4$ units by 24 of 38 patients (63.2\%). Most of these patients $(n=22 / 30 ; 73.3 \%)$ reached this state of disease activity at both time points, FU1 and FU2, respectively. The remaining patients had on average a $60.9 \%$ improvement of their initial BASDAI value and a $62.9 \%$ improvement in patient's global assessment, and continued to participate in the study.

Baseline parameters had no predictive value to indicate high disease activity at FU1 or FU2. However, patients with higher disease activity scores (BASDAI $\geqslant 4$ ) had a tendency to differ from patients with $\mathrm{BASDAI}<4$ units at $\mathrm{FU}$ in disease duration (18.1 years vs 13.7 years, $p=N S$ ) and age (43.4 years vs 37.5 years, $p=N S)$, and were significantly different in their BASFI values (7.1 units vs 4.9 units, $p=0.001$ )

\section{Response}

An ASAS 40\% response was seen in 24 of $38(63.2 \%)$ patients at FU2, in comparison with 28 of $38(73.7 \%)$ patients at FU1 (fig $2 b)(p=0.29)$. Similarly, a "ASAS 5 out of 6" response was achieved in 27 of $38(71.1 \%)$ at FU2 as compared with 29 of 38 (76.3\%) patients at FU1 (fig 2b).
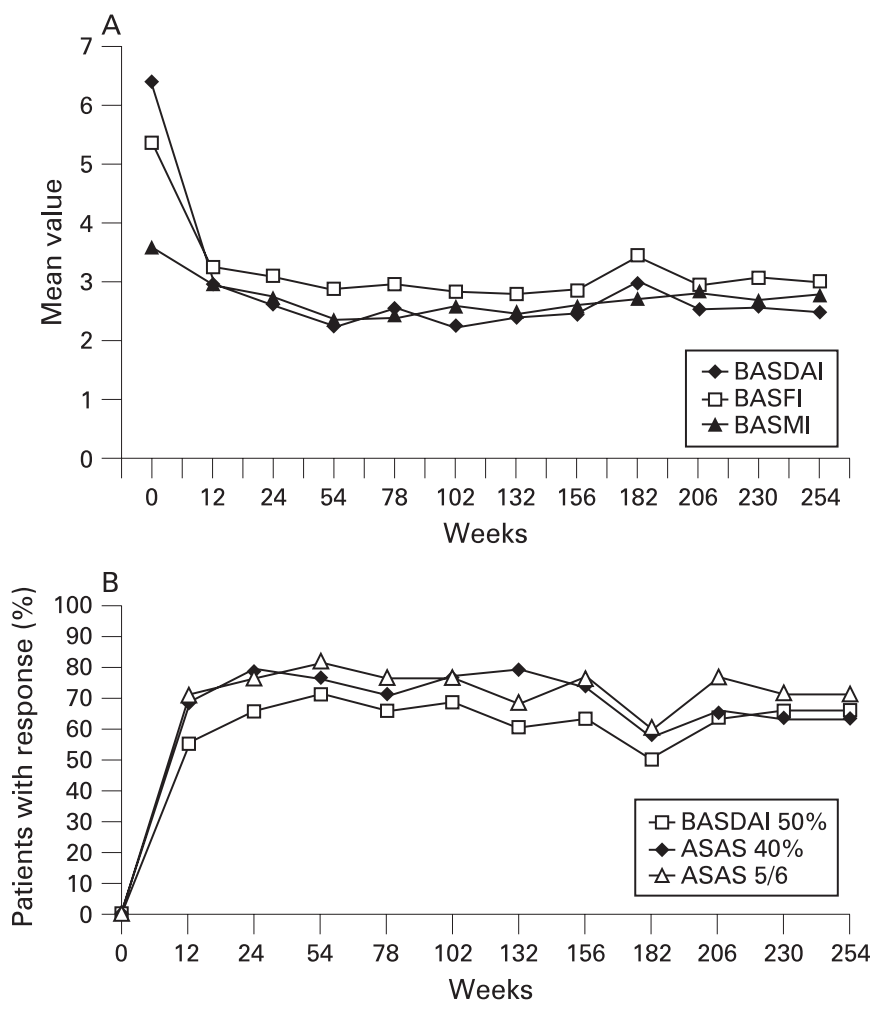

Figure 2 (a) Completer analysis of BASDAI, BASFI and BASMI for all patients $(n=38)$ that completed the entire 5-year study period. For the first 24 weeks of the study (placebo controlled phase), the data are pooled data from all patients under infliximab treatment (initiallyinfliximab and initially-placebo patients). (b) Completer analysis for BASDAI $50 \%$, ASAS $40 \%$ and "ASAS 5 out of 6 " response for all patients $(n=38)$ that completed the entire study period of 5 years.
An ASAS 20\% response was achieved by 36 of 38 patients $(96.7 \%)$ at FU1 and by 32 of 38 patients (84.2\%) at FU2 $(\mathrm{p}=0.13)$, respectively.

A BASDAI $>50 \%$ response at FU2 as compared with BL was found in 25 of 38 patients (65.8\%), similar to FU1 with 24 of 38 $(63.2 \%)$ patients (fig 3$)$.

\section{Responder states over time}

In a more detailed analysis of 25 time points over the whole study period of 5 years ( 24 weeks after start of infliximab treatment, FU1 and all visits from the time point of readministration until the end of the end of the study) it was found that the proportion of ASAS 20 responders showed some variance over time. However, almost all patients reached an ASAS 20\% response at least once within 5 years (table 1 ). Only one patient never had an ASAS 20\% response during the entire study (table 1). The best report of this patient was at 54 weeks when the improvement in this patient's global assessment was $50 \%$, in pain $57.1 \%$ and in stiffness $10 \%$ with only limited worsening of function by $4.7 \%$ was noted.

Importantly, the majority of the 38 patients $(n=22$ patients; $58 \%$ ) showed an ASAS 20\% response at all visits between week 24 and 156 and also between week 218 and 256 of the study (table 1). The ASAS $40 \%$ and the "ASAS 5 out of 6" improvement criteria were also reached in most patients at least once (25 of 38 (65.8\%) and 24 of 38 (63.2\%) patients, respectively).

To make distinctions clinically easier we divided the patients in three groups according to their level and degree of response: group A patients $(n=10)$ were in remission at most time points $(\geqslant 20 / 25$ visits), group $B$ patients $(n=12)$ had a state of low disease activity (BASDAI $<3$ ) at most time points $(\geqslant 20 / 25$ visits), and the remainder was attributed to group $C(n=16)$. The main difference between $\mathrm{A}$ and $\mathrm{B}+\mathrm{C}$ is mainly the mean age (31 vs 41 years, respectively) and the mean disease duration ( 9 vs 17 years). The main difference between groups B and C was function at baseline (mean BASFI 4.8 vs 6,7 , respectively).

Group A differed from B and C mainly in age with 31.2 (6.2) years, 39.5 (7.3) years and 42.9 (6.2) years, respectively ( $\mathrm{p}=0.001$ between $\mathrm{A}-\mathrm{B}$ and $\mathrm{A}-\mathrm{C}$ ) and in disease duration with 9.1 (7.0) years, 16.2 (9.4) years and 17.0 (8.6) years, respectively $(\mathrm{p}=0.02$ between $\mathrm{A}-\mathrm{B}$ and $\mathrm{A}-\mathrm{C})$. The comparison between groups $B$ and $C$ showed a difference in function at baseline with a mean BASFI 4.8 (1.6) vs 6.2 (1.5) respectively, $(p=0.037)$.

Peripheral manifestations, organ involvement and other symptoms Enthesitis was observed in 19 of 38 patients at BL (50\%) as compared with seven at FU 1 and FU 2 (18.4\%), respectively. Peripheral arthritis was seen in 12 of 38 patients at BL (31.6\%) as compared with four patients at FU 1 (10.5\%) and 3 at FU 2 $(7.9 \%)$. However, this tendency was at some variance as only one patient had arthritis at week 54 (2.6\%) but there were five patients with arthritis at week $102(13.2 \%)$ (table 2$)$.

The SF-36 values at FU1 and FU2 remained high (mean scores 42.4 (11.2) and 47.9 (9.9), respectively) as compared with BL (mean score $29.0(7.2))(\mathrm{p}=0.001)$. The physical sum scale was 29.0 (7.2) at BL, 42.4 (11.2) at the end of year 3, and 41.1 (11.9) at the end of year 5 , respectively. The psychological sum scale was 42.1 (12.2) at BL, 48.7 (10.2) at the end of year 3, and 47.9 (9.9) at the end of year 5 , respectively.

A history of anterior uveitis was reported by 17 of 38 patients at $\mathrm{BL}(42 \%)$ but only one had had a flare of anterior uveitis within the last year before inclusion in the study. During year 3 


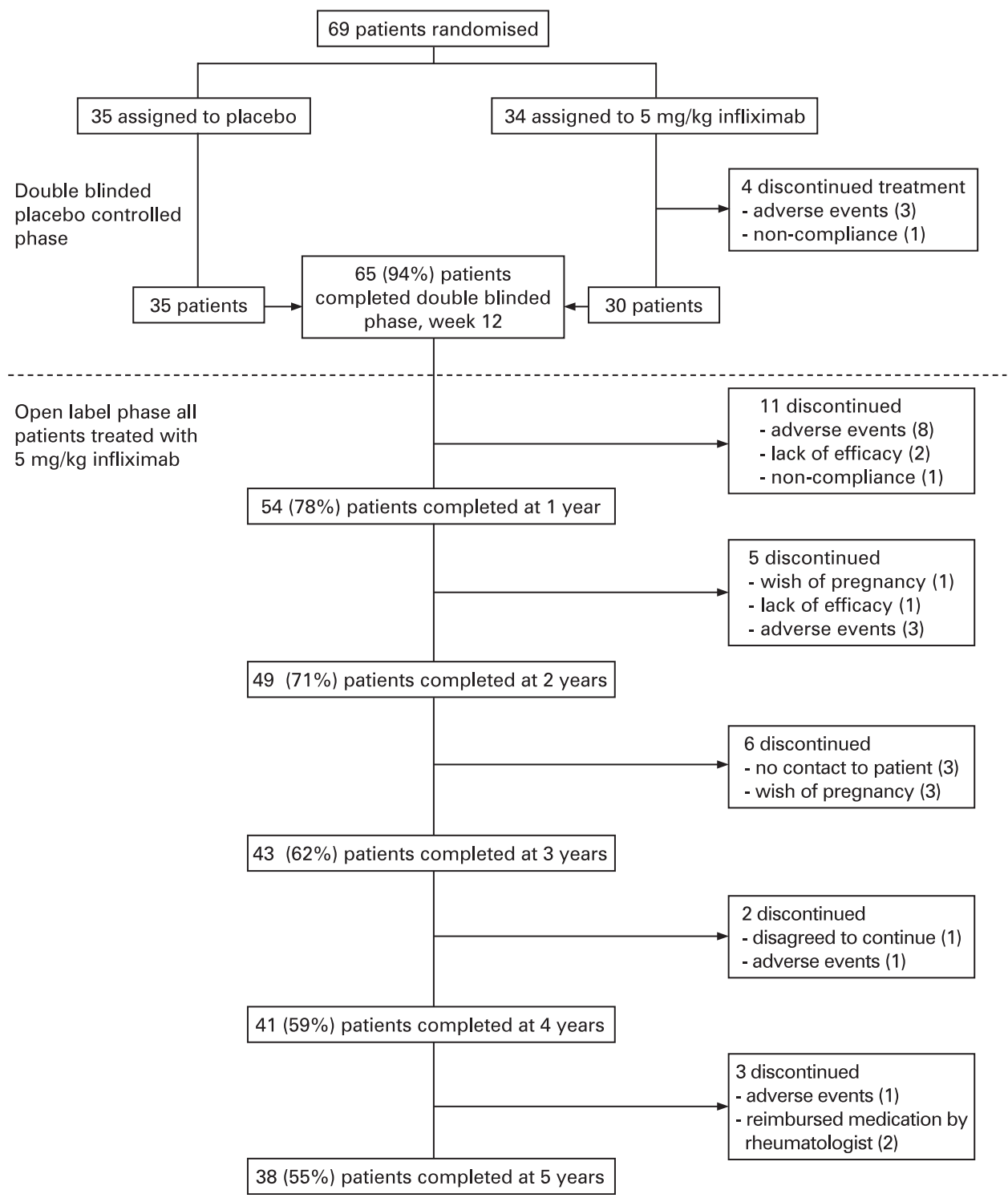

Figure 3 Summary of patient disposition through the entire study period of 5 years.

of the study only one patient had a flare of anterior uveitis, and during years 4 and 5 no patient showed symptoms of anterior uveitis .

Table 1 Cross-section analysis of the response to treatment between week 24 and 156 and also 218 to 256 (25 visits) for all 38 completers included in this study

\begin{tabular}{|c|c|c|c|c|c|c|}
\hline & $\begin{array}{l}\text { Never } \\
\text { n (\%) }\end{array}$ & $\begin{array}{l}>0 \text { and } \\
\leqslant \mathbf{2 5 \%} \\
\text { of all } \\
\text { visits } \\
n(\%)\end{array}$ & $\begin{array}{l}>\mathbf{2 5} \text { and } \\
\leqslant \mathbf{5 0 \%} \\
\text { of all } \\
\text { visits } \\
\mathbf{n}(\%)\end{array}$ & $\begin{array}{l}>\mathbf{5 0} \text { and } \\
\leqslant \mathbf{7 5 \%} \\
\text { of all } \\
\text { visits } \\
\mathbf{n}(\%)\end{array}$ & $\begin{array}{l}>75 \text { and } \\
<100 \% \\
\text { of all } \\
\text { visits } \\
\mathbf{n}(\%)\end{array}$ & $\begin{array}{l}100 \% \\
\text { of all } \\
\text { visits } \\
\mathrm{n}(\%)\end{array}$ \\
\hline ASAS $20 \%$ & $1(2.6)$ & 0 & $2(5.3)$ & $3(7.9)$ & $10(26.3)$ & $22(57.9)$ \\
\hline ASAS $40 \%$ & $3(7.9)$ & $5(13.2)$ & $1(2.6)$ & $4(10.5)$ & $10(26.3)$ & $15(39.5)$ \\
\hline $\begin{array}{l}\text { Partial } \\
\text { remission }\end{array}$ & 22 (57.9) & $2(5.3)$ & 0 & $4(10.5)$ & $6(15.8)$ & $4(10.5)$ \\
\hline $\begin{array}{l}\text { "ASAS } 5 \\
\text { out of } 6 \text { "** }\end{array}$ & $3(7.9)$ & $3(7.9)$ & $3(7.9)$ & $5(13.2)$ & $5(13.2)$ & $19(50.0)$ \\
\hline
\end{tabular}

Numbers are $\mathrm{n}$ of patients, numbers in brackets are $\%$ of patients.

\section{Adverse events}

During the fourth and fifth year of the study, 36 of 38 patients $(94.7 \%)$ reported at least one adverse event. The most frequently reported events were common cold (41\%), bronchitis $(11 \%)$ and increase of liver enzymes (6.5\%).

Six of the 43 patients (14\%) at FU1 reported serious adverse events (SAE) during years 4 and 5 of the study. Four of those were due to hospitalisation for reasons clearly not related to the study drug, according to the investigator, such as trauma. The other two SAEs led to discontinuation of the study: one patient withdrew because of recurrent vaginal infections and the other patient due to repeated infections of the upper respiratory tract. According to the investigator, both those SAEs were thought to be possibly drug related.

\section{DISCUSSION}

This study shows that therapy of AS patients is efficacious and safe over 5 years of almost continuous treatment. There was no indication of loss of response as indicated by the persistent rate of remission and low disease activity. As we had tried to 
Table 2 Longitudinal analysis of disease status for all 38 completers for assessment of the prevalence of similar clinical status at week 12 and other follow-up time points of the study

\begin{tabular}{|c|c|c|c|c|}
\hline & 12 weeks $(95 \% \mathrm{CI})$ & $\begin{array}{l}\text { At all time points } \\
\text { of follow-up }\end{array}$ & $\begin{array}{l}\text { At } 90 \% \text { of the time } \\
\text { points }(95 \% \mathrm{Cl})\end{array}$ & $\begin{array}{l}\text { At } 80 \% \text { of the time points } \\
\text { of follow-up }(95 \% \mathrm{Cl})\end{array}$ \\
\hline Partial remission & $7(18.4 \%)$ (9.2 to 33.4$)$ & $3 / 7$ & $5 / 7(71.4 \%)$ (35.9 to 91.8$)$ & $6 / 7(85.7 \%)(48.7$ to 97.4$)$ \\
\hline BASDAI $<3$ & $21(55.3 \%)$ (39.7 to 69.9$)$ & $12 / 21$ & $16 / 21(76.2 \%)(54.9$ to 89.4$)$ & $19 / 21(90.5 \%)(71.1$ to 97.3$)$ \\
\hline $\mathrm{BASFI}<3$ & $24(63.2 \%)$ (47.3 to 76.6$)$ & $14 / 24$ & $17 / 24(70.8 \%)$ (50.8 to 85.1$)$ & $17 / 24(70.9 \%)(50.8$ to 85.1$)$ \\
\hline No arthritis & $33(86.8 \%)(72.7$ to 94.2$)$ & $24 / 33$ & $31 / 33(93.9 \%)(80.4$ to 98.3$)$ & $32 / 33(97.0 \%)(84.7$ to 99.5$)$ \\
\hline No enthesitis & $29(76.3 \%)(60.8$ to 87.0$)$ & $14 / 29$ & $25 / 29(86.2 \%)(69.4$ to 94.5$)$ & $25 / 29(86.2 \%)(69.4$ to 94.5$)$ \\
\hline No arthritis/enthesitis & $28(73.7 \%)(58.0$ to 85.0$)$ & $14 / 28$ & $22 / 28(78.6 \%)(60.5$ to 89.8$)$ & $23 / 28(82.1 \%)(64.4$ to 92.1$)$ \\
\hline BASDAI/global assessment $<4$ & $25(65.8 \%)(49.9$ to 78.8$)$ & $12 / 25$ & $20 / 25(80.0 \%)(60.9$ to 91.1$)$ & $21 / 25(84.0 \%)(65.3$ to 93.6$)$ \\
\hline $\mathrm{CRP} \leqslant 6 \mathrm{mg} / \mathrm{l}$ & $34(89.5 \%)(75.9$ to 95.8$)$ & $8 / 34$ & $23 / 34(67.6 \%)(50.8$ to 80.9$)$ & $27 / 34(79.4 \%)(63.2$ to 89.7$)$ \\
\hline
\end{tabular}

Numbers are $\mathrm{n}$ of patients, numbers in brackets are $\%$ of patients.

discontinue therapy after 3 years without success we believe that continuous therapy is necessary to achieve a lasting effect in these patients.

The study shows that the degree of response clearly varies among patients. About a third of the patients have remained in a state of remission according to the preliminary ASAS criteria from the beginning. Another third has developed to a state of low disease activity as defined by a BASDAI $<3$, as recently proposed, ${ }^{26}$ also relatively early. However, about $20 \%$ of the patients had a BASDAI $>4$ after 5 years and, thus, still fulfil the initial inclusion criteria. In order to clarify how these patients benefited from anti-TNF therapy we have performed several subanalyses. One important result is that all but one patient have fulfilled the ASAS 20 improvement criteria at least once over time. Another important one is that, on the basis of our analysis, it seems that there are mainly three types of responders: type $\mathrm{A}$ is in clinical remission early and at most time points thereafter; type $B$ has a state of low disease activity at most time points but is not in remission; and type $C$ has limited improvement but does not fulfil the ASAS 20 improvement criteria at all time points, some even only at a few time points. This latter subgroup, which is also characterised by a BASDAI $>4$ at some time points, is usually older, has longer disease duration and higher BASFI scores at the time point of initiation of anti-TNF therapy. This is consistent with our earlier study on prediction of response. ${ }^{27}$ Finally, we like to stress that the doses used in this study has always been the same. Thus, it cannot be excluded that patients would have had better outcomes with higher dosages. As loss of response due to antibody formation has been recently reported ${ }^{28}$ we have to add that in this study, after 3 years, only one patient had developed a significant antibody titre to infliximab ${ }^{26}$ this patient has dropped out in the meantime for other reasons.

A major result of the study is that function as assessed by the BASFI is largely maintained for the study period of 5 years. In the natural course of the disease, according to recent reports, ${ }^{29-31}$ some worsening would have been expected. As function is known to be affected by both disease activity and structure, ${ }^{31}$ the question arises which of those plays the major part. According to our recently published analysis on the radiographs collected in the study over 4 years ${ }^{32}$ it is very likely that the constant suppression of disease activity is essential for the longterm outcome of active AS patients. It is conceivable that continuous physical therapy may also be of importance. Furthermore, there seem to be important differences in comparison with rheumatoid arthritis ${ }^{33}{ }^{34}$ with regard to the influence of anti-TNF therapy on new bone formation.

Another important observation is that, although infliximab has been very effective for improving disease activity and other parameters from the very beginning and lasting over a long period of time, this response seems to be less impressive with respect to spinal mobility (as assessed by BASMI) in this study. There are several explanations for this finding: first, the assessment tool BASMI due to its structure (scorings on a $0-2$ scale, mainly measurement of damage) is known to be not very sensitive to change. Second, most of the patients involved here did not have high BASMI values at baseline. This implies that treatment responses are likely to be even less impressive, especially as compared with other response parameters, such as BASDAI, which had to be high for inclusion in anti-TNF studies. Third, the radiographic damage at baseline, as assessed by the modified Stoke Ankylosing Spondylitis Spinal Score was not very low (11.6 units), and actually comparable with published data from other cohorts (Outcome in Ankylosing Spondylitis International Study), indicating a significant proportion of patients with structural changes at that time point. On the other hand, recent results from the same cohort indicate that there is still some radiographic progression after 4 years of infliximab therapy. ${ }^{35}$ Thus, there is some evidence that infliximab is more effective on disease activity and function than on structural damage. However, there is need for more data to draw final conclusions.

Peripheral arthritis was not a major target in this study, as we had initially concentrated on inflammatory back pain, but 12 patients had reported such symptoms at baseline. At the 5-year follow-up, there were only three patients who reported signs of peripheral arthritis. It should be noted that in our study, peripheral arthritis is documented even if a single finger joint is swollen, and this may include cases of additional osteoarthritis. Accordingly, this is likely to cause some hypersensitivity with regard to the symptom "peripheral arthritis". The numbers of patients with peripheral arthritis during years 1-3 of the study have been previously reported, it was generally rather low over the years. ${ }^{12-14}$

Regarding safety we have reported some serious adverse events early in the study. ${ }^{11-14}$ Over 5 years there were no safety concerns with this limited data set, and this is consistent with recent data from large registries. ${ }^{36}$ Thus, it seems that after the initial years of anti-TNF therapy with infliximab about half of the initial patient cohort are still being successfully treated. In addition, the rate of dropouts tended to decrease during the last 2 years.

Taken together, anti-TNF therapy with infliximab is efficacious and well tolerated in patients with active AS over 5 years. Clinical remission can be achieved in many patients with a convincing safety profile and low rates of drug-related adverse events. Different types of responders can be differentiated.

Acknowledgements: We acknowledge the medical stuff and study nurses of all participating sites for their tireless work and cooperation in this study and especially B. 
Buss, L. Goldschmidt, H.C. Brandt, I-H Song, C. Herz, T. Braun, A Müller, J. Richter, E. Richter, B. Andermann, S. Dyanchenko, C. Pohl and C. Strasser.

Competing interests: Professors Braun and Sieper have received honoraria and grants from Centocor, Schering-Plough, Wyeth, Amgen, and Abbott.

\section{REFERENCES}

1. Braun J, Bollow M, Remlinger G, Eggens U, Rudwaleit M, Distler A, et al. Prevalence of spondylarthropathies in HLA-B27 positive and negative blood donors. Arthritis Rheum 1998;41:58-67.

2. Brandt J, Bollow M, Haberle J, Rudwaleit M, Eggens U, Distler A, et al. Studying patients with inflammatory back pain and arthritis of the lower limbs clinically and by magnetic resonance imaging: many, but not all patients with sacroiliitis have spondyloarthropathy. Rheumatology (Oxford) 1999;38:831-6.

3. Gran JT, Husby G, Hordvik M. Prevalence of ankylosing spondylitis in males and females in a young middle-aged population of Tromso, northern Norway. Ann Rheum Dis 1985; 44:359-67.

4. Saraux A, Guedes C, Allain J, Devauchelle V, Valls I, Lamour A, et al. Prevalence of rheumatoid arthritis and spondyloarthropathy in Brittany, France. Societe de Rhumatologie de l'Ouest. J Rheumatol 1999;26:2622-7.

5. Kobelt G, Andlin-Sobocki P, Brophy S, Jonsson L, Calin A, Braun J. The burden of ankylosing spondylitis and the cost-effectiveness of treatment with infliximab (Remicade). Rheumatology (Oxford) 2004;43:1158-66.

6. Ward MM, Functional disability predicts total costs in patients with ankylosing spondylitis. Arthritis Rheum 2002;46:223-31.

7. Boonen A, van der Heijde D, Landewe R, Spoorenberg A, Schouten H, Rutten-van Molken $\mathrm{M}$, et al. Work status and productivity costs due to ankylosing spondylitis: comparison of three European countries. Ann Rheum Dis 2002;61:429-37.

8. Zink A, Listing J, Klindworth C, Zeidler H. The national database of the German Collaborative Arthritis Centres: I. Structure, aims, and patients. Ann Rheum Dis 2001;60:199-206.

9. Boonen A, Chorus A, Miedema $H$, van der Heijde D, van der Tempel $H$, van der Linden S. Employment, work disability, and work days lost in patients with ankylosing spondylitis: a cross sectional study of Dutch patients. Ann Rheum Dis 2001;60:353-8.

10. Chorus AM, Boonen A, Miedema HS, van der Linden S. Employment perspectives of patients with ankylosing spondylitis. Ann Rheum Dis 2002;61:693-9.

11. Braun J, Brandt J, Listing J, Zink A, Alten R, Golder W, et al. Treatment of active ankylosing spondylitis with infliximab: a randomised controlled multicentre trial. Lancet 2002;359:1187-93.

12. Braun J, Brandt J, Listing J, Zink A, Alten R, Burmester G, et al. Long-term efficacy and safety of infliximab in the treatment of ankylosing spondylitis: an open, observational, extension study of a three-month, randomized, placebo-controlled trial. Arthritis Rheum 2003;48:2224-33.

13. Braun J, Brandt J, Listing J, Zink A, Alten R, Burmester G, et al. Two year maintenance of efficacy and safety of infliximab in the treatment of ankylosing spondylitis. Ann Rheum Dis 2005:64:229-34.

14. Braun J, Baraliakos X, Brandt J, Listing J, Zink A, Alten R, et al. Persistent clinical response to the anti-TNF antibody infliximab in patients with ankylosing spondylitis over 3 years. Rheumatology 2005:44:670-6.

15. Braun J, Baraliakos X, Golder W, Brandt J, Rudwaleit M, Listing J, et al. Magnetic resonance imaging examinations of the spine in patients with ankylosing spondylitis, before and after successful therapy with infliximab: evaluation of a new scoring system. Arthritis Rheum 2003:48:1126-36.

16. Braun J, Brandt J, Listing J, Zink A, Alten R, Burmester G, et al. Two-year maintenance of efficacy and safety of infliximab in the treatment of ankylosing spondylitis. Ann Rheum Dis 2005;64:229-34.

17. Garrett $\mathbf{S}$, Jenkinson T, Kennedy LG, Whitelock H, Gaisford P, Calin A. A new approach to defining disease status in ankylosing spondylitis: the Bath Ankylosing Spondylitis Disease Activity Index. J Rheumatol 1994;21:2286-91.

18. Baraliakos X, Listing J, Brandt J, Rudwaleit M, Sieper J, Braun J. Clinical response to withdrawal of anti-TNF therapy in patients with ankylosing spondylitis (AS) after 3 years of continuous treatment with Infliximab. Arthritis Res Ther 2005;7(R439-R444).
19. Braun J, Pham T, Sieper J, Davis J, van der Linden S, Dougados M, et al. International ASAS consensus statement for the use of anti-tumour necrosis factor agents in patients with ankylosing spondylitis. Ann Rheum Dis 2003;62:81724.

20. Jenkinson TR, Mallorie PA, Whitelock HC, Kennedy LG, Garrett SL, Calin A. Defining spinal mobility in ankylosing spondylitis (AS). The Bath AS Metrology Index. J Rheumatol 1994:21:1694-8.

21. Calin A, Garrett S, Whitelock H, Kennedy LG, O'Hea J, Mallorie P, et al. A new approach to defining functional ability in ankylosing spondylitis: the development of the Bath Ankylosing Spondylitis Functional Index. J Rheumatol 1994;21: 2281-5.

22. Ware JE Jr, Sherbourne CD. The MOS 36-item short-form health survey (SF-36). I. Conceptual framework and item selection. Med Care 1992;30:473-83.

23. Medical Outcome Trust. How to score the SF-36 Health Survey. Boston: Medical Outcome Trust, 1994.

24. Anderson JJ, Baron G, van der Heijde D, Felson DT, Dougados M. Ankylosing spondylitis assessment group preliminary definition of short-term improvement in ankylosing spondylitis. Arthritis Rheum 2001;44:1876-86.

25. Brandt J, Listing J, Sieper J, Rudwaleit M, Van Der Heijde D, Braun J. Development and preselection of criteria for short-term improvement after anti-TNF $\{$ alpha $\}$ therapy in ankylosing spondylitis. Ann Rheum Dis 2004;63:1438-44.

26. Baraliakos X, Listing J, Brandt J, Zink A, Alten R, Burmester G, et al. Clinical response to discontinuation of anti-TNF therapy in patients with ankylosing spondylitis after 3 years of continuous treatment with infliximab. Arthritis Res Ther 2005;7:R43944.

27. Rudwaleit M, Listing J, Brandt J, Braun J, Sieper J. Prediction of a major clinical response (BASDAI 50) to tumour necrosis factor alpha blockers in ankylosing spondylitis. Ann Rheum Dis 2004;63:665-70.

28. de Vries M, Wolbrink G, Stapel S, de Vrieze H, Van Denderen JC, Dijkmans B, et al. Decreased clinical response to infliximab in ankylosing spondylitis is correlated with anti-infliximab formation. Ann Rheum Dis 2007;66:1252-4.

29. Ward MM. Predictors of the progression of functional disability in patients with ankylosing spondylitis. J Rheumatol 2002;29:1420-5.

30. Wanders A, Landewe R, Dougados M, Mielants H, van der Linden S, van der Heijde D. Association between radiographic damage of the spine and spinal mobility for individual patients with ankylosing spondylitis: can assessment of spinal mobility be a proxy for radiographic evaluation? Ann Rheum Dis 2005;64:988-94.

31. Wanders AJ, Landewe RB, Spoorenberg A, Dougados M, van der Linden S, Mielants $\mathrm{H}$, et al. What is the most appropriate radiologic scoring method for ankylosing spondylitis? A comparison of the available methods based on the Outcome Measures in Rheumatology Clinical Trials filter. Arthritis Rheum 2004;50:2622-32.

32. Baraliakos X, Listing J, Brandt J, Rudwaleit M, Sieper J, Braun J. Radiographic progression in patients with ankylosing spondylitis (AS) - results after 4 years of treatment with infliximab. Ann Rheum Dis 2006;65(Suppl. II).

33. van der Heijde D, Klareskog L, Rodriguez-Valverde V, Codreanu C, Bolosiu H, MeloGomes J, et al. Comparison of etanercept and methotrexate, alone and combined, in the treatment of rheumatoid arthritis: two-year clinical and radiographic results from the TEMPO study, a double-blind, randomized trial. Arthritis Rheum 2006;54:1063-74.

34. Landewe R, van der Heijde D, Klareskog L, van Vollenhoven R, Fatenejad S Disconnect between inflammation and joint destruction after treatment with etanercept plus methotrexate: results from the trial of etanercept and methotrexate with radiographic and patient outcomes. Arthritis Rheum 2006;54:3119-25.

35. Baraliakos X, Listing J, Brandt J, Haibel H, Rudwaleit M, Sieper J, et al. Radiographic progression in patients with ankylosing spondylitis after 4 years of treatment with the anti-TNF- $\alpha$ antibody infliximab. Rheumatology (Oxford) 2007(July 10, Epub ahead of print).

36. Dixon W, Watson K, Lunt M, Hyrich K, Silman AJ, Symmons D, et al. Rates of serious infection, including site-specific and bacterial intracellular infection, in rheumatoid arthritis patients receiving anti-tumor necrosis factor therapy: results from the British Society for Rheumatology Biologics Register. Arthritis Rheum 2006;54(Aug:2368-76). 